\title{
Arctiin induces cell growth inhibition through the down-regulation of cyclin D1 expression
}

\author{
YOUICHIROU MATSUZAKI ${ }^{1}$, MAKOTO KOYAMA ${ }^{1}$, TOSHIAKI HITOMI ${ }^{1}$, TOMOYA YOKOTA ${ }^{1}$, \\ MAYUMI KAWANAKA ${ }^{1}$, AKIYOSHI NISHIKAWA ${ }^{2}$, DORIS GERMAIN ${ }^{3}$ and TOSHIYUKI SAKAI ${ }^{1}$
}

\begin{abstract}
${ }^{1}$ Department of Molecular-Targeting Cancer Prevention, Graduate School of Medical Science, Kyoto Prefectural University of Medicine, 465 Kajii-cho Kawaramachi-Hirokoji, Kamigyo-ku, Kyoto 602-8566; ${ }^{2}$ Division of Pathology, National Institute of Health Sciences, 1-18-1 Kamiyoga, Setagaya-ku, Tokyo 158-8501, Japan; ${ }^{3}$ Department of Medicine, Division of Hematology/Oncology, Mount Sinai School of Medicine, One Gustave L. Levy Place, New York, NY 10029, USA
\end{abstract}

Received July 30, 2007; Accepted September 24, 2007

\begin{abstract}
Arctiin is a major lignan constituent of Arctium lappa and has anti-cancer properties in animal models. It was recently reported that arctiin induces growth inhibition in human prostate cancer PC-3 cells. However, the growth inhibitory mechanism of arctiin remains unknown. Herein we report that arctiin induces growth inhibition and dephosphorylates the tumor-suppressor retinoblastoma protein in human immortalized keratinocyte HaCaT cells. We also show that the growth inhibition caused by arctiin is associated with the downregulation of cyclin D1 protein expression. Furthermore, the arctiin-induced suppression of cyclin D1 protein expression occurs in various types of human tumor cells, including osteosarcoma, lung, colorectal, cervical and breast cancer, melanoma, transformed renal cells and prostate cancer. Depletion of the cyclin D1 protein using small interfering RNA-rendered human breast cancer MCF-7 cells insensitive to the growth inhibitory effects of arctiin, implicates cyclin D1 as an important target of arctiin. Taken together, these results suggest that arctiin down-regulates cyclin D1 protein expression and that this at least partially contributes to the anti-proliferative effect of arctiin.
\end{abstract}

\section{Introduction}

The lignans are a group of compounds formed by the condensation of pairs of phenylpropane structures and are

Correspondence to: Dr Toshiyuki Sakai, Department of Molecular-Targeting Cancer Prevention, Graduate School of Medical Science, Kyoto Prefectural University of Medicine, Kawaramachi-Hirokoji, Kamigyo-ku, Kyoto 602-8566, Japan

E-mail: tsakai@koto.kpu-m.ac.jp

Abbreviations: $\mathrm{RB}$, retinoblastoma protein; CDK, cyclindependent kinase; CKI, CDK inhibitor; siRNA, small interfering RNA; GAPDH, glyceraldehyde-3-phosphate dehydrogenase

Key words: arctiin, lignan, cyclin D1, retinoblastoma protein ubiquitously present in a variety of seeds, beans, fruits and vegetables (1). They influence several biological functions, such as hormone metabolism, cell proliferation, transformation and differentiation (1). Arctiin is a lignan constituent of Arctium lappa and exhibits anti-cancer effects in animal models. Takasaki et al reported that arctiin has a remarkable anti-tumor-promoting effect as seen in a two-stage carcinogenesis test of mouse skin tumors induced by 7,12-dimethylbenz $[\alpha]$ anthracene (DMBA) as an initiator and 12-Otetradecanoyl phorbol-13-acetate (TPA) as a promoter by topical and oral administration (2). Hirose et al showed that arctiin has a protective effect on 2-amino-1-methyl-6phenylimidazo[4,5-ß]pyridine (PhIP)-induced carcinogenesis particularly in the mammary gland during the promotion period (3). In addition, it was reported that arctiin induces growth inhibition in human prostate cancer PC-3 cells and that it is associated with up-regulation of the anti-adhesion mucin MUC-1 gene (4). However, the growth inhibitory mechanisms of arctiin remain unknown.

Cell cycle progression is regulated by proteins called cyclins and cyclin-dependent kinases (CDKs), which associate with each other (5). Cyclins activate their partners, CDKs and direct their enzymes to specific substrates. Cyclin D1/D2/D3-CDK4/6 and cyclin E/A-CDK2 play important roles in promoting the G1-to-S phase transition of the cellcycle by phosphorylating the tumor-suppressor retinoblastoma protein (RB) (5). The process of cyclin-dependent activation of CDKs is counterbalanced by CDK inhibitors (6). Two families of CDK inhibitors were identified in mammalian cells and each has a different mode of action. One group, composed of related proteins known as $\mathrm{p} 21^{\mathrm{WAF} 1}, \mathrm{p} 27^{\mathrm{Kip} 1}$ and p57 Kip2, inhibit cyclin E/A-CDK2 complexes (7). The second family of CDK inhibitors is also called the INK4 protein family and its members, p15 $15^{\text {INK4b }}, \mathrm{p} 16^{\text {INK4a }}$, p $18^{\text {INK4c }}$ and p19 ${ }^{\text {INK4d }}$, directly bind to CDK4/6 and are specific inhibitors of cyclin D-dependent kinases (8).

In the present study, we analyzed the growth inhibitory mechanisms of arctiin using human malignant tumor cells. We showed that arctiin down-regulates the cyclin D1 protein expression and that this is at least partially related to the antiproliferative effect of arctiin. 


\section{Materials and methods}

Cell culture and reagents. The human immortalized keratinocyte cell line HaCaT (a gift from Dr N.E. Fusenig, German Cancer Research Center, Heidelberg, Germany), the human osteosarcoma cell line MG63, the human lung cancer cell line A549, the human colorectal cancer cell line HCT116, the human cervical cancer cell line HeLa, the human breast cancer cell line MCF-7 and the human transformed renal cell line 293T were maintained in DMEM with $10 \%$ fetal bovine serum. The human melanoma cell line UACC-62 and the human prostate cancer cell line DU145 were maintained in RPMI-1640 medium with $10 \%$ fetal bovine serum. All of these cells were incubated at $37^{\circ} \mathrm{C}$ in a humidified atmosphere of $5 \% \mathrm{CO}_{2}$. Arctiin (Alps Pharmaceutical, Japan) was dissolved in dimethyl sulfoxide (DMSO).

Analysis of cell cycle progression. Cells were treated with Triton X-100 and their nuclei were stained with propidium iodide before DNA content was measured using a BectonDickinson FACSCalibur (Becton-Dickinson, Mountain View, CA, USA). At least 10,000 cells were counted and the ModFit LD ver. 2.0 software package (Becton-Dickinson, Franklin Lakes, NJ, USA) was used to analyze the data.

Protein isolation and Western blot analysis. Cells were lysed by lysis buffer (50 mM Tris- $\mathrm{HCl}, \mathrm{pH} 7.5$ and $0.1 \%$ SDS). The protein extract was then boiled for $5 \mathrm{~min}$ and loaded onto a $12 \%$ polyacrylamide gel for $\mathrm{p} 15^{\mathrm{INK} 4 \mathrm{~b}}, \mathrm{p} 18^{\mathrm{INK} 4 \mathrm{c}}$, p19 ${ }^{\mathrm{INK} 4 \mathrm{~d}}, \mathrm{p} 21^{\mathrm{WAF} 1 / \mathrm{Cip} 1}, \mathrm{p} 27^{\mathrm{Kip} 1}, \mathrm{p} 57^{\mathrm{Kip} 2}, \mathrm{CDK} 2, \mathrm{CDK} 4, \mathrm{CDK} 6$, cyclin A, cyclin D1, cyclin D3, cyclin E and $\alpha$-tubulin detection or $7 \%$ polyacrylamide gel for RB detection, electrophoresed and transferred to a nitrocellulose membrane. A mouse monoclonal antibody against human cyclin D1 (DCS-6, MBL, Nagoya, Japan) and CDK6 (DCS-83, MBL) and rabbit polyclonal antibodies against human p15 ${ }^{\mathrm{INK} 4 \mathrm{~b}}$ (C-20, Santa Cruz Biotechnology, CA, USA), p18 ${ }^{\text {INK4c }}$ (N-20, Santa Cruz Biotechnology), p19 ${ }^{\text {INK4d }}$ (C-20, Santa Cruz Biotechnology), p21 WAF1/Cip1 (C-19, Santa Cruz Biotechnology), p27 Kip1 (C-19, Santa Cruz Biotechnology), p57 Kip2 (P-0357, Sigma, MO, USA), CDK2 (M-2, Santa Cruz Biotechnology), CDK4 (H22, Santa Cruz Biotechnology), cyclin A (C-19, Santa Cruz Biotechnology), cyclin D3 (C-16, Santa Cruz Biotechnology), cyclin E (HE-12, Santa Cruz Biotechnology), RB (PM14001A, Pharmingen, NJ, USA), phospho-RB (Ser ${ }^{780}$ ) (\#9307, Cell Signalling, MA, USA) and $\alpha$-tubulin (Oncogene Research Product, CA, USA) were used as primary antibodies. Signals were then detected with an enhanced chemiluminescence system (ECL, Amersham Pharmacia Biotech, NJ, USA).

RNA isolation and Northern blot analysis. Total RNA was isolated from HaCaT cells treated with or without $100 \mu \mathrm{M}$ arctiin for the indicated times using a Sepasol RNA isolation kit (Nakalai Tesque Inc., Kyoto, Japan) according to the manufacturer's instructions. Total RNA was fractionated on $1 \%$ agarose gels, transferred to nylon filters and hybridized with a cyclin D1 cDNA probe (a gift from Dr R.G. Pestell, Georgetown University School of Medicine, Washington, DC, USA) according to standard procedures (9). The same filter was a

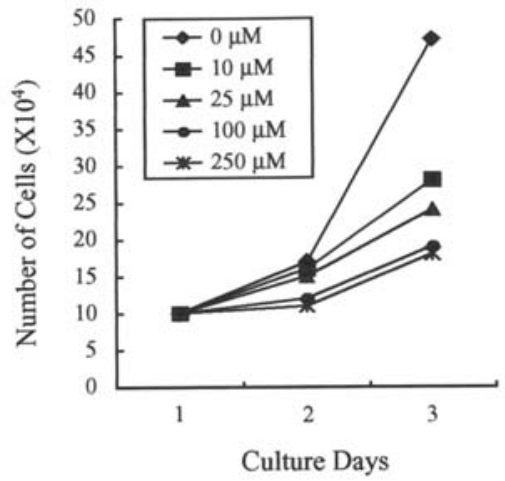

b
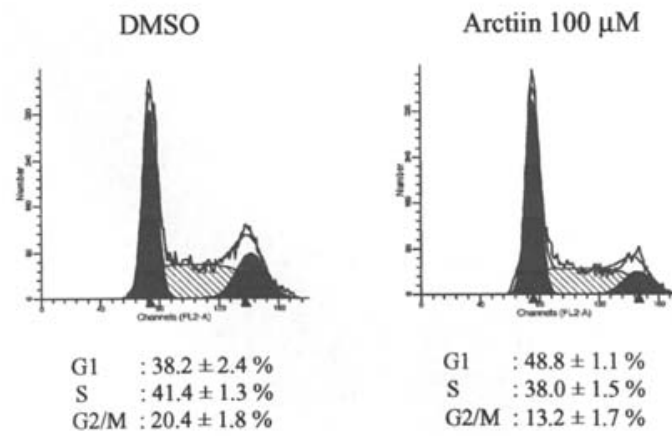

Figure 1. The effect of arctiin on the growth and cell cycle progression of $\mathrm{HaCaT}$ cells. (a) $\mathrm{HaCaT}$ cells were plated at $1 \times 10^{5}$ cells in 25 -mm-diameter dishes. Twenty-four hours after plating, various concentrations of arctiin were added to the culture medium. From the first to the third day after plating, the number of viable cells was counted by the trypan blue dye exclusion test. (b) Unsynchronized HaCaT cells were exposed to $100 \mu \mathrm{M}$ arctiin for $48 \mathrm{~h}$ and the DNA content of the cells was determined by flow cytometry. The data represent the means of triplicate experiments and are shown as the means $\pm \operatorname{SD}(n=3)$.

rehybridized with a glyceraldehyde-3-phosphate dehydrogenase (GAPDH) cDNA probe for internal control and mRNA levels were determined using a Fuji Image Analyzer Bas 2000 (Fujix, Tokyo, Japan).

siRNA transfection. Cyclin D1 siRNA\#1 (\#16810, Ambion, TX, USA) and siRNA\#2 (\#118854, Ambion) and a negative control siRNA (\#4611, Ambion) were used. The targeted exon of cyclin D1 siRNA\#1 or \#2 is exon 3 or 5 , respectively. MCF-7 cells were plated at $5 \times 10^{4}$ cells in 24-well plates and transfected with $0.5 \mu \mathrm{M}$ of siRNA using lipofectamine 2000 reagent (Invitrogen, CA, USA).

\section{Results}

Arctiin induces growth inhibition in HaCaT cells. We examined the effect of arctiin on the proliferation of human immortalized keratinocyte $\mathrm{HaCaT}$ cells. Arctiin inhibited the growth of HaCaT cells in a dose-dependent manner. The number of viable cells treated with $10,25,100$ or $250 \mu \mathrm{M}$ arctiin for $48 \mathrm{~h}$ was $60,51,40$, or $38 \%$ of the number of viable cells treated with vehicle only for $48 \mathrm{~h}$, respectively (Fig. 1a). 
The cells treated with $100 \mu \mathrm{M}$ arctiin were close to being viable. Arctiin at 100-250 $\mu \mathrm{M}$ exhibited a maximum growth inhibitory effect, although it did not completely inhibit cell growth (Fig. 1a). To investigate the effect of arctiin on cell cycle progression, the DNA content of cell nuclei was measured by flow cytometric analysis. Treatment with $100 \mu \mathrm{M}$ arctiin for $48 \mathrm{~h}$ significantly $(\mathrm{P}<0.05)$ increased the percentage from 38.2 to $48.8 \%$ in the G1 phase (Fig. 1b).

Arctiin decreases cyclin D1 protein levels in HaCaT cells. Cyclin-CDKs play important roles in promoting the G1-to-S phase transition of the cell cycle by phosphorylating the RB protein (5) and the process of cyclin-dependent activation of CDKs is counterbalanced by CDK inhibitors (6). We screened for the expression of CDK inhibitors to clarify the molecular mechanisms underlying arctiin-induced growth inhibition in HaCaT cells. Whole-cell lysates were isolated after $0,6,12,24$ and $48 \mathrm{~h}$ of culturing with $100 \mu \mathrm{M}$ arctiin and were then subjected to immunoblotting. As shown in Fig. 2a, treatment with arctiin had no effect on the expression of the p5 $7^{\mathrm{Kip} 2}$ protein. Arctiin slightly affected the expression of p15 $5^{\text {INK } 4 b}, \mathrm{p} 18^{\text {INK4c }}$ and p19 INK4d and down-regulated the expression of the $\mathrm{p} 21^{\mathrm{WAF} 1 / \mathrm{Cip} 1}$ protein after $48 \mathrm{~h}$ of treatment. Weak down-regulation of the $\mathrm{p} 27^{\mathrm{Kip} 1}$ protein was also observed from 24 to $48 \mathrm{~h}$ after exposure to arctiin. The amount of p $16^{\text {INK4a }}$ protein was below the detection limit (data not shown). The G1-to-S phase transition is also regulated by CDKs (5). We also examined whether the expression of CDKs can be altered by treatment with arctiin. The expression of the CDK4 protein was not altered by the treatment and arctiin slightly changed the expression of CDK2 and CDK6 (Fig. 2a). Then, we investigated the effect of arctiin on the expression of cyclins. Among the cyclins examined, the amount of cyclin D1 started to decrease after $24 \mathrm{~h}$ of culturing and further decreased to undetectable levels after $48 \mathrm{~h}$. Weak down-regulation of the cyclin D3 and A protein was observed $48 \mathrm{~h}$ after treatment with arctiin. However, arctiin did not affect the expression of the cyclin E protein (Fig. 2a) and we could not detect the cyclin D2 protein.

The time course study indicated that arctiin strongly decreased the cyclin D1 protein in a time-dependent manner. To investigate whether arctiin down-regulates the cyclin D1 protein in a dose-dependent fashion, whole-cell lysates were isolated after 24 or $48 \mathrm{~h}$ of culturing with $0,10,25,100 \mu \mathrm{M}$ arctiin and then subjected to immunoblotting. After $24 \mathrm{~h}$ of culturing, the expression of the cyclin D1 protein was significantly repressed by $100 \mu \mathrm{M}$ arctiin (Fig. 2b). After $48 \mathrm{~h}$, arctiin strongly down-regulated the cyclin D1 protein expression in a dose-dependent manner and arctiin at 25 and $100 \mu \mathrm{M}$ decreased the amount of cyclin D1 protein to undetectable levels (Fig. 2b). These results indicated that arctiin down-regulates the expression of cyclin D1 protein in a time- and dose-dependent manner. Taken together with the results presented in Figs. 1a and 2b, we suggest that arctiininduced growth inhibition is correlated with the arctiin-induced down-regulation of cyclin D1 protein. Then, we examined the effect of arctiin on the cyclin D1 mRNA level. Total RNAs were isolated after $0,6,12,24$ and $48 \mathrm{~h}$ of culturing with or without $100 \mu \mathrm{M}$ arctiin and then subjected to Northern blot analysis. As shown in Fig. 2c, arctiin slightly affected the a

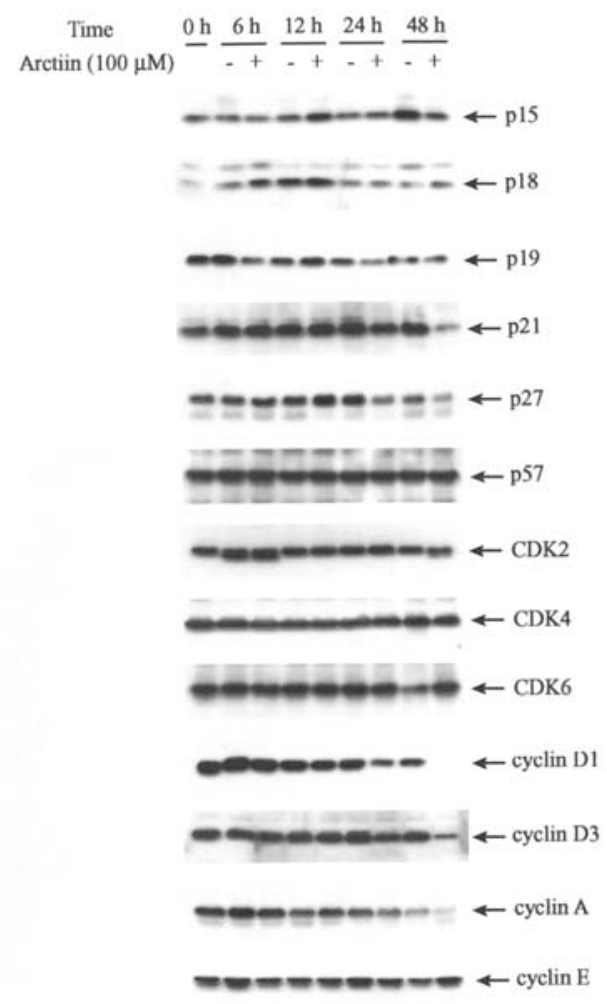

b

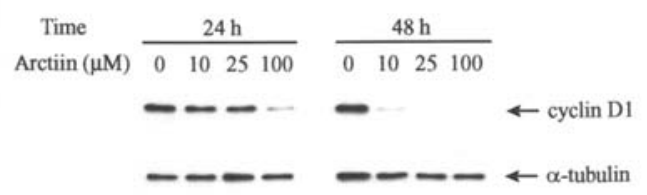

c

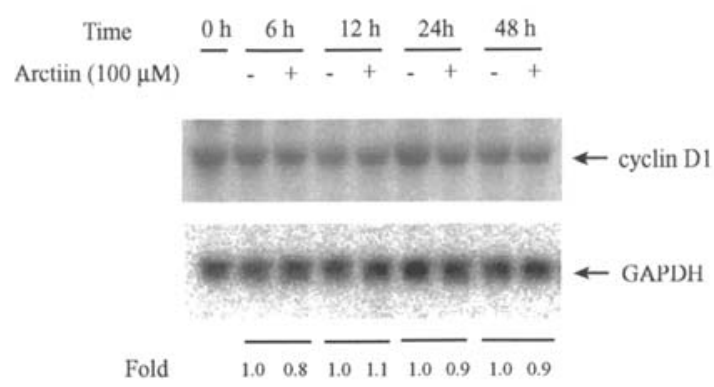

Figure 2. The effect of arctiin on the expression of CDK inhibitors, CDKs and cyclins in HaCaT cells. (a) HaCaT cells were exposed to DMSO (-) or $100 \mu \mathrm{M}$ arctiin (+) and were lysed at the indicated times after treatment. Western blotting was performed to examine the expression of $\mathrm{p} 15^{\mathrm{INK} 4 \mathrm{~b}}$, p1 $8^{\mathrm{INK} 4 \mathrm{c}}, \mathrm{p} 19^{\mathrm{INK} 4 \mathrm{~d}}, \mathrm{p} 21^{\mathrm{WAF} 1 / \mathrm{Cip} 1}, \mathrm{p} 27^{\mathrm{Kip} 1}, \mathrm{p} 57^{\mathrm{Kip} 2}, \mathrm{CDK} 2, \mathrm{CDK} 4, \mathrm{CDK} 6$, cyclin D1, cyclin D3, cyclin A and cyclin E. An antibody to $\alpha$-tubulin was used as a loading control. (b) $\mathrm{HaCaT}$ cells were treated with various concentrations of arctiin for 24 or $48 \mathrm{~h}$ and the expression of cyclin D1 protein was then examined in Western blotting. (c) HaCaT cells were treated with $100 \mu \mathrm{M}$ arctiin for the indicated times and the expression of cyclin D1 mRNA was examined by Northern blot analysis. The transcript is $\sim 4.3 \mathrm{~kb}$. The mRNA level of cyclin D1 was standardized against that of GAPDH. Data shown below the blots represent fold induction in the mRNA expression and each value was compared with that of the control without arctiin which was estimated as 1.0 . 
a

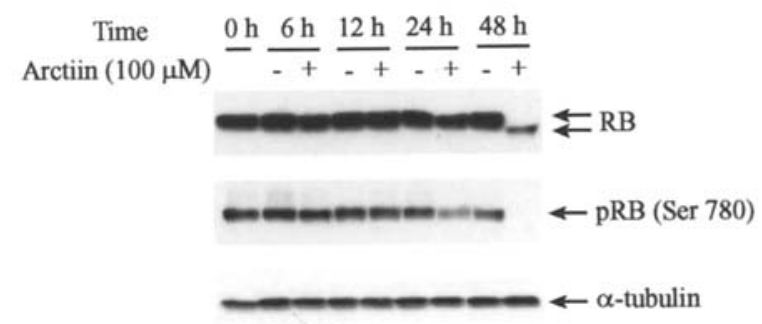

b
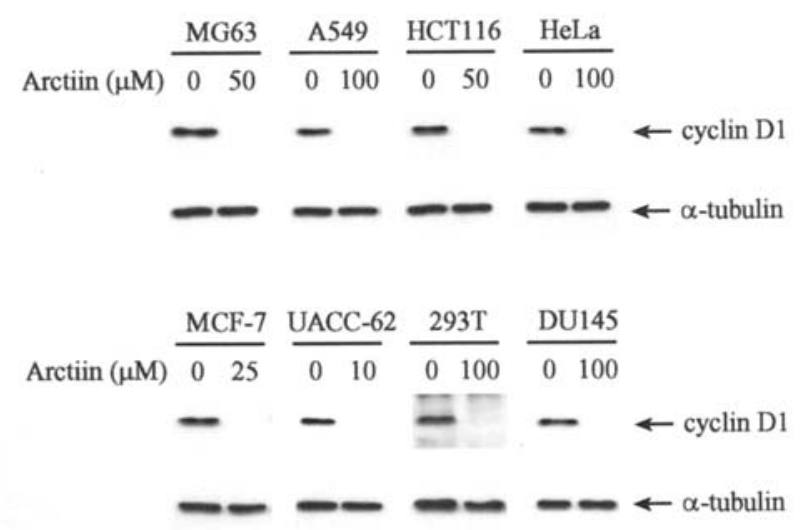

Figure 3. The effect of arctiin on the expression of RB and phosphorylated $\mathrm{RB}$ in HaCaT cells. (a) HaCaT cells were exposed to DMSO (-) or $100 \mu \mathrm{M}$ arctiin $(+)$ and were lysed at the indicated times after treatment. Western blotting was then carried out using antibodies against RB and phospho-RB (Ser 780). (b) The human osteosarcoma cell line MG63, the human lung cancer cell line A549, the human colorectal cancer cell line HCT116, the human cervical cancer cell line HeLa, the human breast cancer cell line MCF-7, the human melanoma cell line UACC-62, the human transformed renal cell line $293 \mathrm{~T}$ and the human prostate cancer cell line DU145 were treated with various concentrations of arctiin for $48 \mathrm{~h}$ and the expression of cyclin D1 protein was then examined by Western blotting.

amount of cyclin D1 mRNA. This result suggested that arctiin post-transcriptionally down-regulates the cyclin D1 protein expression.

Arctiin dephosphorylates $R B$ protein in HaCaT cells. Since cyclin D1 activates CDK4/6, we investigated whether the phosphorylation status of RB is altered in arctiin-treated $\mathrm{HaCaT}$ cells. RB is a key substrate for various cyclin-CDK complexes and specific sites on it are phosphorylated by distinct cyclin-CDK complexes $(10,11)$. Therefore, we used an anti-phospho-RB (Ser 780) antibody, which specifically recognizes CDK4/6-phosphorylated residues Ser 780 on RB $(10,11)$. Western blot analysis showed that from 6 to $12 \mathrm{~h}$ after treatment with arctiin, the phosphorylation status (Ser 780) of RB was not changed (Fig. 3a). However, the expression of phosphorylated $\mathrm{RB}$ protein recognized by anti-phospho-RB
(Ser 780) started to decrease after $24 \mathrm{~h}$ of culturing and further decreased to undetectable levels after $48 \mathrm{~h}$ (Fig. 3a). Then, we used an anti-RB antibody, which recognizes the RB protein regardless of its phosphorylation status. Western blot analysis indicated that $48 \mathrm{~h}$ after treatment with arctiin, the amount of $\mathrm{RB}$ protein slightly decreased and the RB protein band shifted from a hyperphosphorylated form to a hypophosphorylated form (Fig. 3a). These results indicated that arctiin dephosphorylates RB protein in HaCaT cells.

Arctiin decreases cyclin D1 protein levels in various types of human tumor cells. To clarify whether the down-regulation of cyclin D1 by arctiin is a general event, we subsequently examined the effect of arctiin on the cyclin D1 expression in other human tumor cell lines. For this investigation, we used the osteosarcoma cell line MG63, the lung cancer cell line A549, the colorectal cancer cell line HCT116, the cervical cancer cell line HeLa, the breast cancer cell line MCF-7, the melanoma cell line UACC-62, the human transformed renal cell line 293T and the prostate cancer cell line DU145. As shown in Fig. 3b, arctiin inhibited the expression of cyclin D1 protein in all of these cell lines, suggesting that the arctiin-induced down-regulation of cyclin D1 protein is an ubiquitous event in human tumor cells.

Depletion of cyclin DI protein renders MCF-7 cells insensitive to the growth inhibitory effect of arctiin. Finally, we examined whether cyclin D1 is involved in cell growth inhibition by arctiin in MCF-7 cells. As shown in Fig. 3b, arctiin down-regulates the cyclin D1 protein expression in MCF-7 cells. However, the amount of cyclin D3 protein was not altered by arctiin (data not shown) and the cyclin D2 protein was not detected in MCF-7 cells. If cyclin D1 is one of the important targets of arctiin, cyclin D1-depleted MCF-7 cells are expected to be insensitive to the action of arctiin. To test this hypothesis, we used cyclin D1 siRNAs to specifically deplete cyclin D1. As shown in Fig. 4a, treatment with cyclin D1 siRNA\#1 or siRNA\#2, respectively, almost depleted the cyclin D1 protein. However, the cyclin D1 siRNAs had no effect on the expression of cyclin D3 protein (Fig. 4a). As shown in Fig. 4c, cyclin D1 siRNA-treated cells proliferate more slowly than mock- or control siRNA-treated cells. To characterize the cyclin D1 siRNA-treated cells further, we performed FACS analysis (Fig. 4b). The cyclin D1 siRNAtreated cells showed a slightly but significantly $(\mathrm{P}<0.05)$ increased percentage of G1 phase compared to mock- or control siRNA-treated cells. Then we examined the effect of arctiin on cyclin D1-depleted cells. As shown in Figs. 4c and d, arctiin inhibited growth in mock- or control siRNA-treated MCF-7 cells. On the other hand, arctiin did not induce growth inhibition in cyclin D1 siRNA-treated cells (Figs. 4c and d). Collectively, along with the fact that arctiin down-regulates the cyclin D1 protein in MCF-7 cells (Fig. 3b), suggest that cyclin D1 is one of the key targets of arctiin for its growth inhibitory function.

\section{Discussion}

Arctiin is a major lignan of Arctium lappa. Our results indicated that arctiin inhibited cell growth and dephosphorylated 


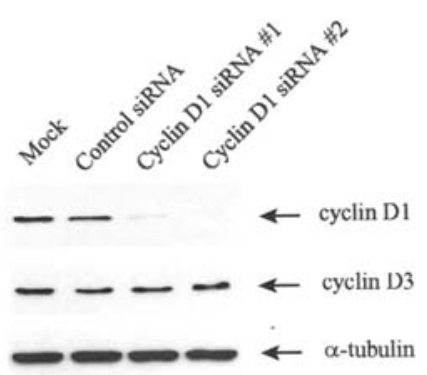

b

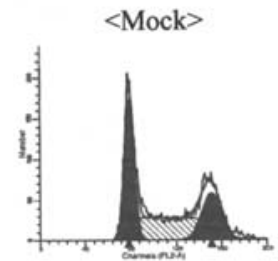

$\begin{array}{l:l}\text { G1 } & 37.7 \pm 1.1 \% \\ \text { G } 2 / \mathrm{M} & 39.4 \pm 1.1 \% \\ 22.9 \pm 1.6 \%\end{array}$

$<$ Cyclin D1 siRNA\#1>

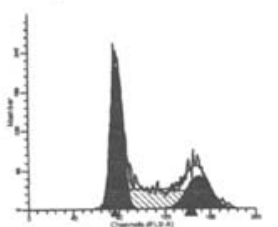

$\begin{array}{ll}\text { G1 } 1 & 45.3 \pm 0.7 \% \\ \text { G } 2 / \mathrm{M} & 34.5 \pm 0.8 \% \\ 2 & 20.2 \pm 0.4 \%\end{array}$

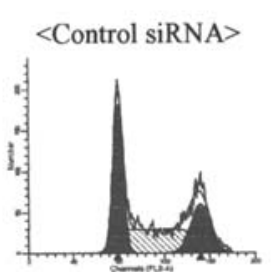

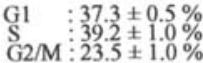

$<$ Cyclin D1 siRNA\#2>

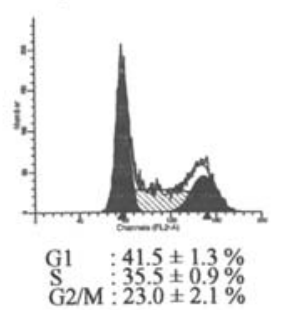

c
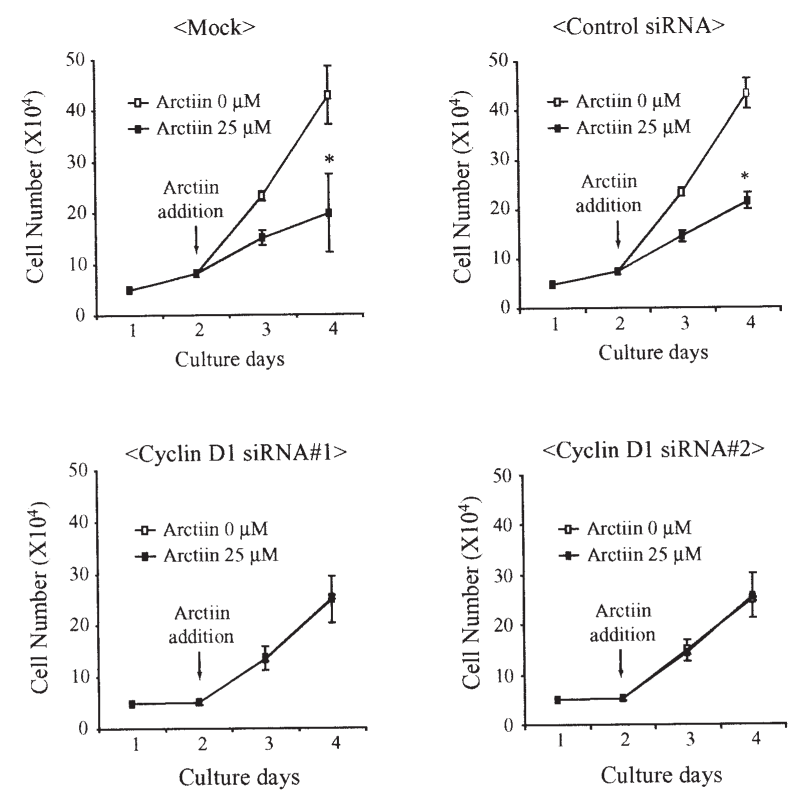

d

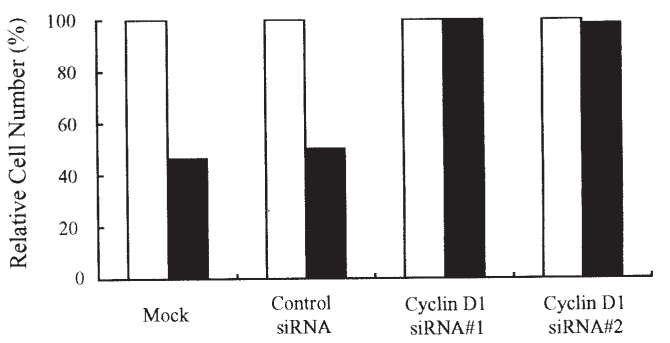

Figure 4. Depletion of cyclin D1 protein renders MCF-7 cells insensitive to the growth inhibitory effect of arctiin. (a) MCF-7 cells were plated at $5 \times 10^{4}$ cells in 24-well plates and transfected with $0.5 \mu \mathrm{M}$ of siRNA. Cyclin D1 siRNA\#1 and siRNA\#2 and a negative control siRNA were used. Mock, MCF-7 cells treated with lipofectamine 2000 reagent only. Twenty-four hours after transfection, cell lysates were prepared and the expression of cyclin D1 or D3 protein was examined by Western blotting. (b) Forty-eight hours after transfection the DNA content of the cells was determined by flow cytometry. The data represent the means of triplicate experiments and are shown as the means \pm SD (n=3). (c) Twenty-four hours after transfection, arctiin at $25 \mu \mathrm{M}$ was added and cell growth was compared with a control culture. The data represent the means of triplicate experiments and are shown as the means $\pm \mathrm{SD}$ ( $\mathrm{n}=3$ ). ${ }^{*} \mathrm{P}<0.05$. (d) Relative cell viability of MCF-7 cells treated with DMSO ( $\square$ ) or $25 \mu \mathrm{M}$ arctiin ( $\square$ ) for $48 \mathrm{~h}$.

the RB protein in human immortalized keratinocyte HaCaT cells. We also found that the growth inhibition induced by arctiin was correlated with the down-regulation of the cyclin D1 protein. Arctiin-induced cyclin D1 suppression occurred in multiple human tumor cells, including osteosarcoma, lung, colorectal, cervical and breast cancer, melanoma, transformed renal cells and prostate cancer. Furthermore, the depletion of the cyclin D1 protein using cyclin D1 siRNAs rendered human breast cancer MCF-7 cells insensitive to the growth inhibitory effects of arctiin, suggesting that cyclin D1 is one of the important targets of arctiin. Taken together, these results suggested that arctiin down-regulates the cyclin D1 protein expression and that this at least partially contributes to the growth inhibition caused by arctiin.

Arctiin induced anti-cancer effects in animal models such as a significant anti-tumor-promoting effect in a two-stage carcinogenesis model of mouse skin tumors induced by DMBA and TPA (2). Hirose et al reported that arctiin inhibited
PhIP-induced mammary carcinogenesis, particularly during the promotion period (3). These studies suggested that the anti-cancer effect of arctiin mainly resides in its anti-tumorpromoting function. On the other hand, several studies reported that cyclin D1 is an important molecule for tumor promotion. Robles et al showed that cyclin D1 deficiency reduced skin tumor development in TPA-treated ras transgenic mice in a two-stage carcinogenesis model using DMBA and TPA (12). These results suggested that cyclin D1 has a role in promoting tumor growth induced by TPA in mouse skin. Furthermore, Qiu et al found that a higher expression of cyclin D1/CDK4 occurred in rat mammary gland carcinomas induced by PhIP (13). Therefore, our present observation that arctiin down-regulates the cyclin D1 protein expression may provide a clue for solving the mechanism of an arctiin-induced anti-tumor promoter function.

We indicated that the depletion of cyclin D1 protein renders MCF-7 cells insensitive to the growth inhibitory effects of 
arctiin in Fig. 4. To investigate whether overexpression of cyclin D1 resists the growth inhibitory effect of arctiin, we examined the effect of arctiin on cyclin D1-overexpressing cells using human breast cancer cell line T-47D-based stable clones that overexpress HA-tagged cyclin D1 protein (14). However, the expression of the overexpressed cyclin D1 protein was also down-regulated by arctiin and the endogeneous cyclin D1 protein (data not shown). As a result, the growth inhibition rate of cyclin D1-overexpressing cells by arctiin was almost equivalent to that of parental cells (data not shown).

Cyclin D1, a regulator of the cell-cycle transition from G1-to-S phase, forms a holoenzyme with CDK4/6 that phosphorylates RB. Overexpression of cyclin D1 promotes cell-cycle progression through the $\mathrm{G} 1$ phase $(8,15)$ and contact-independent growth (16). Genetic alterations in the regulatory components that regulate the G1-to-S phase transition in the cell-cycle frequently occur in human cancers (17). Cyclin D1 is overexpressed in many types of human tumors, including those of the breast, esophagus, lung, head and neck, colon and prostate (18-28). For example, the cyclin D1 gene is amplified and overexpressed in $50 \%$ of human breast cancers $(22,29,30)$ and its expression is associated with the early onset of disease and risk of tumor progression and metastasis $(27,31)$. Transgenic mice that overexpress cyclin D1 in mammary glands develop breast cancer, suggesting that cyclin D1 functions as an oncogene (32). On the other hand, mice lacking cyclin D1 are resistant to oncogene-induced tumorigenesis, including ras-induced skin tumors (12) and ErbB2 or ras-induced mammary tumor formation (33). Therefore, regulated agents of the cyclin D1 expression may contribute to new strategies for the prevention or therapy of malignancies, which we term 'gene-regulating chemoprevention or chemotherapy' $(34,35)$. Arctiin, which down-regulates the cyclin D1 protein expression, may be a representative of generegulating chemopreventive or chemotherapeutical agents.

\section{Acknowledgements}

This work was supported in part by the Ministry of Education, Culture, Sports, Science and Technology of Japan and by a grant (H11-Seikatsu-018) for Research on Environmental Health from the Ministry of Health, Labor and Welfare of Japan. We are grateful to Yuuki Takaoka for the technical support.

\section{References}

1. Adlercreutz H: Phytoestrogens and prevention of cancer. In: Food Factors for Cancer Prevention Ohigashi H, Osawa T, Terao J, Watanabe S and Yoshikawa T (eds), Springer-Verlag, Berlin, pp587-592, 1997.

2. Takasaki M, Konoshima T, Komatsu K, Tokuda H and Nishino H: Anti-tumor-promoting activity of lignans from the aerial part of Saussurea medusa. Cancer Lett 158: 53-59, 2000.

3. Hirose M, Nishikawa A, Shibutani M, Imai T and Shirai T: Chemoprevention of heterocyclic amino-induced mammary carcinogenesis in rats. Environ Mol Mutagen 39: 271-278, 2002.

4. Huang DM, Guh JH, Chueh SC and Teng CM: Modulation of anti-adhesion molecule MUC-1 is associated with arctiin-induced growth inhibition in PC-3 cells. Prostate 59: 260-267, 2004.

5. Sherr CJ: Mammalian G1 cyclins. Cell 73: 1059-1065, 1993.

6 . Sherr CJ and Roberts JM: Inhibitors of mammalian G1 cyclindependent kinases. Genes Dev 9: 1149-1163, 1995.
7. Harper JW and Elledge SJ: CDK inhibitors in development and cancer. Curr Opin Genet Dev 6: 56-64, 1996.

8. Sherr CJ and Roberts JM: CDK inhibitors: positive and negative regulators of G1-phase progression. Genes Dev 13: 1501-1512, 1999.

9. Sambrook J and Russell DW: Molecular Cloning: A Laboratory Manual. First edition., Cold Spring Harbor Laboratory Press, New York, pp7.42-7.44, 2001.

10. Kitagawa M, Higashi H, Jung HK, Suzuki-Takahashi I, Ikeda M, Tamai K, Kato J, Segawa K, Yoshida E, Nishimura S and Taya Y: The consensus motif for phosphorylation by cyclin D1-CDK4 is different from that for phosphorylation by cyclin A/E-CDK2 . EMBO J 15: 7060-7069, 1996.

11. Zarkowska T and Mittnacht S: Differential phosphorylation of the retinoblastoma protein by G1/S cyclin-dependent kinases. J Biol Chem 272: 12738-12746, 1997.

12. Robles AI, Rodriguez-Puebla ML, Glick AB, Trempus C, Hansen L, Sicinski P, Tennant RW, Weinberg RA, Yuspa SH and Conti CJ: Reduced skin tumor development in cyclin D1deficient mice highlights the oncogenic ras pathway in vivo. Genes Dev 12: 2469-2474, 1998.

13. Qiu C, Shan L, Yu M and Snyderwine EG: Deregulation of the cyclin D1/Cdk4 retinoblastoma pathway in rat mammary gland carcinomas induced by the food-derived carcinogen 2-amino-1methyl-6-phenylimidazo(4,5-ß)pyridine. Cancer Res 63: 5674-5678, 2003.

14. Pirkmaier A, Yuen K, Hendley J, O'Connell MJ and Germain D: Cyclin D1 overexpression sensitizes breast cancer cells to fenretinide. Clin Cancer Res 9: 1877-1884, 2003.

15. Pestell RG, Albanese C, Reutens AT, Segall JE, Lee RJ and Arnold A: The cyclins and cyclin-dependent kinase inhibitors in hormonal regulation of proliferation and differentiation. Endocr Rev 20: 501-534, 1999.

16. Resnitzky D and Reed SI: Different roles for cyclins D1 and E in regulation of the G1-to-S transition. Mol Cell Biol 15: 3463-3469, 1995.

17. Diehl JA: Cycling to cancer with cyclin D1. Cancer Biol Ther 1: 226-231, 2002.

18. Gillett C, Fantl V, Smith R, Fisher C, Bartek J, Dickson C, Barnes D and Peters G: Amplification and overexpression of cyclin D1 in breast cancer detected by immunohistochemical staining. Cancer Res 54: 1812-1817, 1994.

19. Bartkova J, Lukas J, Muller H, Lutzhoft D, Strauss M and Bartek J: Cyclin D1 protein expression and function in human breast cancer. Int J Cancer 57: 353-361, 1994

20. Bartkova J, Lukas J, Strauss M and Bartek J: The PRAD-1/ cyclin D1 oncogene product accumulates aberrantly in a subset of colorectal carcinomas. Int J Cancer 58: 568-573, 1994.

21. Bartkova J, Lukas J, Muller H, Strauss M, Gusterson B and Bartek J: Abnormal patterns of D-type cyclin expression and G1 regulation in human head and neck cancer. Cancer Res 55: 949-956, 1995.

22. Dickson C, Fantl V, Gillett C, Brookes S, Bartek J, Smith R, Fisher C, Barnes D and Peters G: Amplification of chromosome band 11q13 and a role for cyclin D1 in human breast cancer. Cancer Lett 90: 43-50, 1995.

23. Adelaide J, Monges G, Derderian C, Seitz JF and Birnbaum D: Oesophageal cancer and amplification of the human cyclin D gene CCND1/PRAD1. Br J Cancer 71: 64-68, 1995.

24. Caputi M, Groeger AM, Esposito V, Dean C, De Luca A, Pacilio C, Muller MR, Giordano GG, Baldi F, Wolner E and Giordano A: Prognostic role of cyclin D1 in lung cancer. Relationship to proliferating cell nuclear antigen. Am J Respir Cell Mol Biol 20: 746-750, 1999.

25. Nishida N, Fukuda Y, Komeda T, Kita R, Sando T, Furukawa M, Amenomori M, Shibagaki I, Nakao K, Ikenaga M and Ishizaki K: Amplification and overexpression of the cyclin D1 gene in aggressive human hepatocellular carcinoma. Cancer Res 54: 3107-3110, 1994

26. Gumbiner LM, Gumerlock PH, Mack PC, Chi SG, deVere White RW, Mohler JL, Pretlow TG and Tricoli JV: Overexpression of cyclin D1 is rare in human prostate carcinoma. Prostate 38: 40-45, 1999.

27. Drobnjak M, Osman I, Scher HI, Fazzari M and Cordon-Cardo C: Overexpression of cyclin D1 is associated with metastatic prostate cancer to bone. Clin Cancer Res 6: 1891-1895, 2000.

28. Arber N, Hibshoosh H, Moss SF, Sutter T, Zhang Y, Begg M, Wang S, Weinstein IB and Holt PR: Increased expression of cyclin D1 is an early event in multistage colorectal carcinogenesis. Gastroenterology 110: 669-674, 1996. 
29. McIntosh GG, Anderson JJ, Milton I, Steward M, Parr AH, Thomas MD, Henry JA, Angus B, Lennard TW and Horne CH: Determination of the prognostic value of cyclin D1 overexpression in breast cancer. Oncogene 11: 885-891, 1995.

30. Hosokawa Y and Arnold A: Mechanism of cyclin D1 (CCND1/ PRAD1) overexpression in human cancer cells: analysis of allele-specific expression. Genes Chromosomes Cancer 22: 66-71, 1998.

31. Jares P, Fernandez PL, Campo E, Nadal A, Bosch F, Aiza G, Nayach I, Traserra J and Cardesa A: PRAD-1/cyclin D1 gene amplification correlates with messenger RNA overexpression and tumor progression in human laryngeal carcinomas. Cancer Res 54: 4813-4817, 1994.
32. Wang TC, Cardiff RD, Zukerberg L, Lees E, Arnold A and Schmidt EV: Mammary hyperplasia and carcinoma in MMTVcyclin D1 transgenic mice. Nature 369: 669-671, 1994.

33. Yu Q, Geng Y and Sicinski P: Specific protection against breast cancers by cyclin D1 ablation. Nature 411: 1017-1021, 2001.

34. Sakai T: Molecular cancer epidemiology - the present status and future possibilities. Jpn J Hyg 50: 1036-1046, 1996.

35. Matsuzaki Y and Sakai T: INK4 family - a promising target for gene-regulating chemoprevention and molecular-targeting prevention of cancer. Environ Health Prev Med 10: 72-77, 2005. 